\title{
Genotype-specific habitat selection and thermal ecology in Nucella lapillus (L.) (the dogwhelk)
}

\author{
D. J. HARRIS* \& J. S. JONES \\ Department of Genetics and Biometry, Univesity College London, 4 Stephenson Way, London NW1 2HE, U.K.
}

\begin{abstract}
Nucella lapillus is a marine gastropod found all around the British coastline. Populations frequently display great polymorphism in the shape and colour of the shells. Shell shape is related to wave exposure but the forces maintaining colour polymorphisms are less clear. Populations from the north coast of Cornwall are shown to exhibit genotype-specific microhabitat partitioning, with lighter colour morphs being relatively commoner in sunnier sites and on average spending more time in the sun than darker morphs. This type of habitat selection has been claimed to be important in the maintenance of genetic variation and may explain some of the colour polymorphisms seen.
\end{abstract}

Keywords: colour morphs, ecology, habitat selection, Nucella lapillus, population, thermal stress.

\section{Introduction}

The dogwhelk Nucella lapillus is found in abundance around the British Isles. On rocky shores it extends across the eulittoral zone, from above the mid-tide level to the low water mark, on all but the most exposed (where it retreats to available nooks and crannies) or the most sheltered shores. It is usually found in large numbers and displays a startling diversity in the shape and colour of the shell. As early as 1838 Forbes \& Hanley noted that 'so manifold are the guises in which this shell presents itself that, were it not that its great abundance and the facility with which it is acquired, have enabled naturalists to perceive the connecting links of the very different looking specimens, their specific individuality would assuredly have been denied'. What maintains this diversity?

Breeding experiments in the closely related Nucella emarginata show that shell colour is genetically controlled (Palmer, 1984). The only environmental agent known to be correlated with colour and banding patterns in dogwhelks is wave exposure (Berry \& Crothers, 1974). Dogwhelk on more sheltered shores tend to be white and unbanded. This association is slight and has many exceptions. It is also not immediately apparent how shell colour might affect the ability to cope with wave action, or why dogwhelks

*Correspondence: British Museum (Natural History), Molecular Biology Unit, Cromwell Road, South Kensington, London SW7 5BD, U.K. might choose to occupy more sheltered or less sheltered sites because of it.

It is, however, well known in land molluscs that solar radiation affects habitat choice. In the snail Cepaea nemoralis the importance of shelter from the sun increases in summer months (Chang \& Emlen, 1993). More heavily pigmented morphs suffer higher heat loads when exposed to direct solar radiation, and this affects activity and survival rates (reviewed in Jones et al., 1977). This leads to differential microhabitat partitioning. It is often claimed that such habitat selection is important in the maintenance of genetic variation, particularly when habitat selection is genotype-specific (Jones \& Probert, 1980; Hedrick, 1986).

The intertidal zone is a thermally stressful place for gastropods (Etter, 1988), so much so that the foraging cycle of dogwhelks is closely linked to the weather (Burrows \& Hughes, 1989). We set out to investigate its thermal ecology and the possibility of genotypespecific habitat selection. We followed an approach similar to that of Jones (1982) in which Cepaea shells were marked with a paint that fades in the sun.

\section{Materials and methods}

Eighteen dogwhelk populations were investigated from near Gwithian (National Grid reference SW 582 423) to Watergate Bay (National Grid reference SW 843 662 ) in north Cornwall, a distance of approximately 40 $\mathrm{km}$. A single area of $1.5 \mathrm{~m}^{2}$ was chosen in which dog- 
whelks were abundant. Fifty $1 \mathrm{~cm}^{2}$ spots of green paint were placed at random on the rocks within each population at low tide. The paint was made from a yellow cellulose base paint mixed with toluidine blue powder (Sigma Chemical Company), and fades from green to yellow at a rate which depends on the amount of solar radiation received (Jones, 1982). The degree of fading can then be compared with a prepared chart made by serial dilution of the green paint with the yellow base and scored from 1 (green) to 10 (yellow). This paint is unaffected by seawater. All the sites were painted on sunny days in August 1993, and then scored approximately $48 \mathrm{~h}$ later (to within an hour), giving a sample average for the fading score of each Nucella habitat. The frequencies of shell colour morphs of the dogwhelks were then recorded. As the dark morphs are very distinct, whereas the light morphs vary from snow white to light brown, the populations were split into just two groups, dark and light. In spite of the somewhat arbitrary nature of this classification, there were no real difficulties in separating the dogwhelks into phenotypically distinct entities in north Cornwall. This separation depends much more on shell colour than on shell banding. The rare pink and orange forms (which never made up more than 2 per cent of a population) were not used, nor was the black and white striped shell pattern which is unique to the Newquay area and is also found only in small numbers. For each of the 18 sites a mean paint fading score for the rocks was recorded along with the proportions of light and dark morphs (Table 1).

At Newquay Bay (National Grid reference SW 813 619) a further experiment was carried out. Dogwhelks from an isolated rock outcrop of approximately $5 \mathrm{~m}$ by $5 \mathrm{~m}$ were all marked with a small spot of green paint on the lowest whorl of the shell. After 3 days the degree of fading was recorded, as was the shell colour. This was to show any genotype-specific differerences that might exist between the lighter and darker morphs (Table 2). It was assumed from studies of Cepaea (Jones, 1982) that the small paint mark would not alter the dogwhelks behaviour.

\section{Results}

Table 1 shows the association between rock fading score and snail phenotype frequency. There is a highly significant correlation between the proportion of lighter morphs and increased fading of the paint on the rocks; $r$ (Spearman's) $=0.60$ (Fig. 1). Light-coloured dogwhelks are, it seems, commoner in sunny places. This is not an effect of a gradual change in morph frequency from north to south which is, by chance, accompanied by a change in climate: the frequency of
Table 1 Locations and National Grid references (SW square) of the 18 populations of Nucella lapillus

\begin{tabular}{llllrl}
\hline Location & Grid ref. & R & SD & $N$ & $\%$ L \\
\hline Fox Hole & 843662 & 3.91 & 1.6 & 95 & 64.2 \\
Zacry's Island & 833638 & 4.57 & 2.1 & 95 & 68.4 \\
Lusty Glaze & 823625 & 3.96 & 1.4 & 108 & 63.0 \\
Criggars & 817624 & 2.14 & 3.7 & 87 & 29.9 \\
Tolcarne Beach & 818622 & 2.43 & 2.8 & 101 & 36.6 \\
Tolcarne Point & 816620 & 2.41 & 3.0 & 103 & 67.0 \\
Killacourt & 813618 & 2.11 & 3.7 & 71 & 64.8 \\
Island House & 811619 & 3.04 & 1.6 & 117 & 61.5 \\
Towan Beach & 811618 & 2.68 & 2.5 & 74 & 45.9 \\
IRB Station & 809619 & 2.62 & 2.2 & 77 & 22.1 \\
Newquay Harbour & 809620 & 2.84 & 2.9 & 85 & 25.9 \\
St. Agnes & 720518 & 7.20 & 2.9 & 76 & 97.4 \\
Porthtowan & 689480 & 9.00 & 4.5 & 107 & 43.9 \\
Portreath & 654456 & 1.35 & 3.4 & 52 & 26.9 \\
The Cleaders & 580429 & 3.96 & 2.6 & 69 & 79.7 \\
Godrevy Cove & 581428 & 5.73 & 1.9 & 50 & 90.0 \\
Godrevy Rocks & 582426 & 7.48 & 2.0 & 100 & 90.8 \\
Magow Rocks & 582423 & 6.97 & 2.1 & 86 & 90.7 \\
\hline
\end{tabular}

$R$ is the mean fade score for the rocks at each site, and SD the standard deviation.

$N$ is the number of dogwhelks at each site with $\% \mathrm{~L}$ the proportion of dogwhelks which had light shells.

Table 2 Relative paint fading scores of 202 light-coloured Nucella lapillus compared with 78 dark ones from the same site at Newquay

\begin{tabular}{ccc}
\hline Paint fading score & Light morph & Dark morph \\
\hline 1 & 0 & 0 \\
2 & 5 & 4 \\
3 & 33 & 34 \\
4 & 58 & 14 \\
5 & 40 & 11 \\
6 & 30 & 7 \\
7 & 8 & 3 \\
8 & 22 & 5 \\
9 & 2 & 0 \\
10 & 4 & 0 \\
\hline
\end{tabular}

Paint fades from 1 (green) to 10 (yellow) in sunlight.

the light morph varies, with no consistent geographical pattern, from 0.22 to 0.97 (Fig. 2).

Table 2 gives the fading score of light and dark snails at the Newquay site. There is a significant difference in mean fading of light and dark shells: light shells fade, on the average, to paint score $5.01(\mathrm{SE}= \pm 0.12)$ and dark shells to paint score 4.15 ( $\mathrm{SE}= \pm 0.18: t=3.691$, $P<0.001)$. Lighter morphs appear on average to be spending more time in the sun than darker ones. 


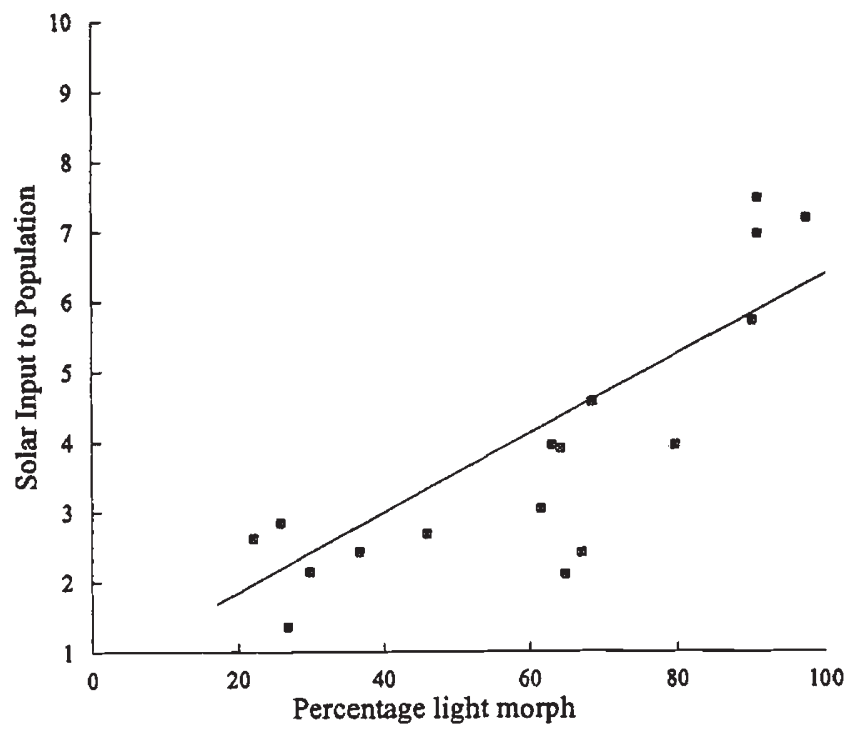

Fig. 1 Graph showing the correlation between mean paint fading score of the rocks and the proportion of ligher morphs of Nucella lapillus at each site.

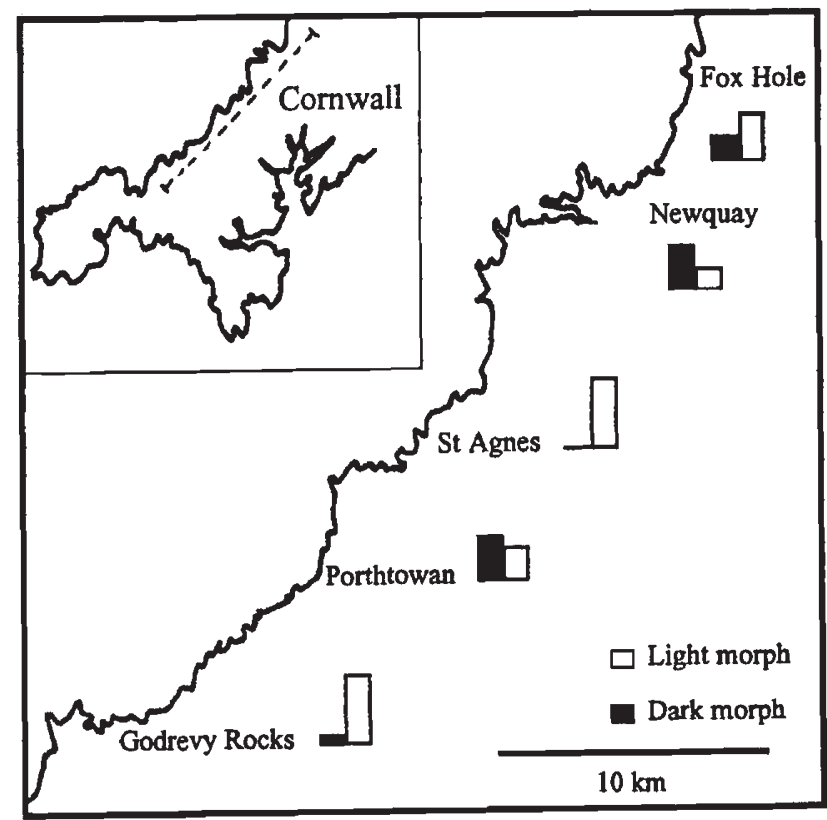

Fig. 2 Proportions of light and dark morphs of Nucella lapillus from populations along the north coast of Cornwall from Godrevey to Watergate Bay.

\section{Discussion}

Dogwhelks, like other marine gastropods, suffer from desiccation at low tide especially on hot, dry days. Snails on shores with less wave action might experience more thermal stress than do those on an exposed shore (Etter, 1988). Exposed shores may be splashed by waves more at low tide. An increase in the severity of thermal stress is expected to favour lighter shell colours, as they reflect radiation. This might keep body temperature down. Etter $(1988)$ showed that when dogwhelks were placed in strong sunlight, darker morphs heated up more quickly than light morphs and that this led to an increase in desiccation and mortality. Dogwhelks in shaded crevices stayed cooler than those in the sun.

Populations along the north coast of Cornwall show a positive correlation between increased solar input (as measured by paint fading on rocks) and the frequency of lighter morphs. In sunnier places the frequency of lighter morphs is higher, perhaps because of differential thermal stress. On wave-exposed shores dogwhelks are largely confined to rock crevices (Cooke, 1915). This might explain the correlation between wave action and colour morph frequency: snails exposed to wave action are forced to shelter in shady places.

The experiment at Newquay Bay shows that there is a significant tendency for darker morphs to stay out of the sun, presumably to reduce heat load. This confirms that microhabitat partitioning is taking place, as in Cepaea (Jones, 1982).

Other factors will no doubt influence the distribution of colour morphs. The rare pink and orange forms, and the great variety of banding patterns, may demand an explanation outside thermoecology. Because Nucella lapillus has nonplanktonic larvae, and the adults are sessile (moving a few metres only; Hughes, 1972), there is minimal gene flow giving an opportunity for the accumulation of local genetic differences. Local forms, such as the black and white striped shell pattern found around Newquay, may become common through drift. Selective predation is unlikely to be an important factor in determining colour variation; two important predators, the crabs Carcinus maenas and Micropipus puber, lack the necessary visual equipment (Hughes \& Elner, 1979). Berry (1983) found no correlation between shell and substrate colour, and studies by Roland (1976) and Berry (1983) show that shell colour is not affected by diet. Assortative mating seems unlikely as it has not been detected in laboratory populations (Berry \& Crothers, 1974). The age of snails also plays a role in distribution: younger dogwhelks prefer more open places (Hughes et al., 1992).

Shell shape is likely to complicate the role of colour in the dogwhelks' thermoecology. Whelks from wavesheltered shores generally have thicker shells and smaller apertures than those from wave-exposed shores (Crothers, 1985). On sheltered shores thicker shells give protection from crabs whereas larger aperture and foot size help prevent dislodgement on exposed shores. Larger apertures may lead to increased desiccation during thermal stress. High- 
spired, conical shells reduce the areas exposed to solar radiation and thus help prevent thermal stress (Vermeij, 1993). This shape is characteristic of littorinid snails from upper intertidal areas in the tropics (Vermeij, 1978). Differences in population density also induce marked differences in shell form (Boulding \& Hay, 1993) as do adaptations between populations living among boulders or on rock faces (Atkinson \& Newbury, 1984). As all these factors are inter-related, vary with overall size and with shell wear, it is very difficult to separate them, and each may interact with the colour of the shell to give a population-specific response to thermal stress. Any of these environmental factors could explain the unusual result from Porthtowan $(\mathrm{R}=9.0, \% \mathrm{~L}=43.9)$. Nevertheless, this study shows that thermal ecology is one factor controlling the distribution of colour morphs in Nucella lapillus. There also appears to be genotypicspecific habitat selection. This may promote genetic polymorphism (Hedrick, 1990). Differential behaviour of the various morphs may help to explain the extensive polymorphism of this species.

\section{Acknowledgements}

We thank Matthew Hutchings and Chris Hayes for assistance in the field in Cornwall, and James Mallet for statistical advice.

\section{References}

ATKINSON, W. D. AND NEWBURY, S. F. 1984. The adaptations of the rough winkle Littorina rudis, to dessication and to dislodgement by wind and waves. J. Anim. Ecol., 53, 93-105.

BERRY, R. J. 1983. Polymorphic shell banding in the dogwhelk, Nucella lapillus. J. Zool. Lond., 200, 455-470.

BERRY, R. J. AND CROTHERS, J. H. 1974. Visible variation in the dogwhelk, Nucella lapillus. J. Zool. Lond., 174, 123-148.

BOULDING, E. G. AND HAY, T. K. 1993. Quantitative genetics of shell form of an intertidal snail: constraints on short-term response to selection. Evolution, 47, 576-592.
BURROWS, M. T. AND HUGHES, R. N. 1989. Natural foraging of the dogwhelk, Nucella lapillus (L.); the weather and whether to feed. J. Moll. Stud., 55, 285-295.

CHANG, H. W. AND EMLEN, J. M. 1993. Seasonal variation of microhabitat distribution of the polymorphic land snail Cepaea nemoralis, Oecologia, 93, 501-507.

COOKE, A. H. 1915. The geological distribution of Purpura lapillus. Proc. Malac. Soc. Lond., 11, 192-209.

CROTHERS, J. H. 1985. Dogwhelks: an introduction to the biology of Nucella lapillus. Field Studies, 6, 291-360.

ETTER, R. J. 1988. Physiological stress and colour polymorphism in the intertidal snail Nucella lapillus. Evolution, 42, $660-680$.

FORBES, E. AND HANLEY, s. 1838. A History of British Mollusca and Their Shells, vol. 3, pp. 380-387. J. Van Voorst, London.

HEDRICK, P. W. 1986. Genetic polymorphism in heterogeneous environments: a decade later. Ann. Rev. Ecol. Syst., 17, 535-566.

HEDRICK, P. W. 1990. Genotypic-specific habitat selection: a new model and its application. Heredity, 65, 145-149.

HUGHES, R. N. 1972. Annual production of two Nova Scotian populations of Nucella lapillus. Oecologia, 8, 356-370.

HUGHES, R. N., BURROWS, M. T. AND ROGERS, S. E. 1992. Ontogenetic changes in foraging behaviour of the dogwhelk Nucella lapillus. J. Exp. Mar. Biol. Ecol., 155, 199-212.

HUGHES, R. N. AND ELNER, R. 1979. Tactics of a predator, Carcinus maenas, and morphological responses of the prey, Nucella lapillus. J. Anim. Ecol., 48, 65-78.

JONES, J. S. 1982. Genetic differences in individual behaviour associated with shell polymorphism in the snail Cepaea nemoralis. Nature, 298, 749-750.

JONES, J. S., LEITH, B. H. AND RAWLINGS, P. A. 1977. Polymorphism in Cepaea: a problem with too many solutions? Ann. Rev. Ecol. Syst., 8, 109-143.

JONES, J. S. AND PROBERT, R. F. 1980. Habitat selection maintains a deleterious allele in a heterogeneous environment. Nature, 287, 632-633.

PALMER, A. R. 1984. Species cohesiveness and genetic control of shell colour and form in Thais emarginata: preliminary results. Malacologia, 25, 477-491.

Rowland, M. J. 1976. Factors Affecting Variation in Natural Populations of the Dogwhelk Thais lapillus. Ph.D. Thesis, University of Wales, Aberystwyth.

VERMEIJ, G. J. 1978. Biogeography and Adaptation: Patterns of Marine Life. Harvard University Press, Cambridge, MA.

VERmeIJ, G. J. 1993. A Natural History of Shells. Princeton University Press, New Jersey. 